\title{
Global Patterns of Child Health: The Role of Nutrition
}

\author{
Benjamin Caballero \\ Center for Human Nutrition, J ohns Hopkins University, Baltimore, Md., USA
}

\section{Key Words}

Child · Nutrition · Growth · Diet

\begin{abstract}
Almost two-thirds of the deaths of children around the world are directly or indirectly associated with nutritional deficiencies. Both protein-energy malnutrition and micronutrient deficiencies increase the risk of death from common diseases such as acute gastroenteritis, pneumonia and measles. Iron deficiency anemia is estimated to affect almost $25 \%$ of the world's population (equivalent to 3.5 billion people) resulting in high economic costs by adding to the burden on healthcare services, affecting learning in school and reducing adult productivity. Dietary practices frequently seen in older children and adolescents from industrialized countries, leading to frequent consumption of often nutrient-poor foods, may also put them at risk of micronutrient deficiencies. Marginal nutrient deficiencies in the developed world are increasingly accepted as risk factors for the development of chronic disease such as cardiovascular disease or some cancers.
\end{abstract}

Copyright $\odot 2002$ S. Karger AG, Basel

In the developing world, eliminating nutritional deficiencies will be a major advance in reducing child mortality and improving quality of life by reducing the overall burden of disease in early life. The slow, but sustained global improvement in child survival is creating a new set of challenges for childhood nutrition, namely, to ensure a normal rate of growth and development of surviving infants and children. The emerging problem of non-communicable diseases of the adult (diabetes, obesity, cardiovascular disease) and its relationship with early malnutrition raises the alarming possibility that future generations of children who suffered nutritional deficiencies early in life will reach adulthood with an increased risk for chronic disease [1].

Throughout the globe it is vital that parents, healthcare workers and teachers remain focused on the task of preventing poor nutrition during the infant, child and adolescent years. Strategies to reduce the risk arising from poor nutrition during infancy or childhood include nutrition education, school-based interventions, and food fortification.

\section{Background}

Available data on global trends of childhood mortality over the past two decades indicate a moderate, but consistent decline in infant and under-5 mortality rates. The reduction in deaths from infectious diseases (acute gastroenteritis, pneumonia, measles, parasitic infections) is likely to be due, at least in part, to the relative success of immunization, nutrient supplementation, promotion of breast-feeding, and improvements in primary healthcare. Similarly, the prevalence of chronic malnutrition (stunt-

\section{KARGER \\ Fax +4161306 1234 \\ E-Mail karger@karger.ch \\ www. karger.com

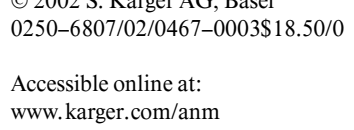

Benjamin Caballero

Center for Human Nutrition, Johns Hopkins University

615 N. Wolfe St.

Baltimore, MD 21205 (USA)

Tel. +1 410614 4070, Fax +1 410955 0195, E-Mail caballero@jhu.edu 


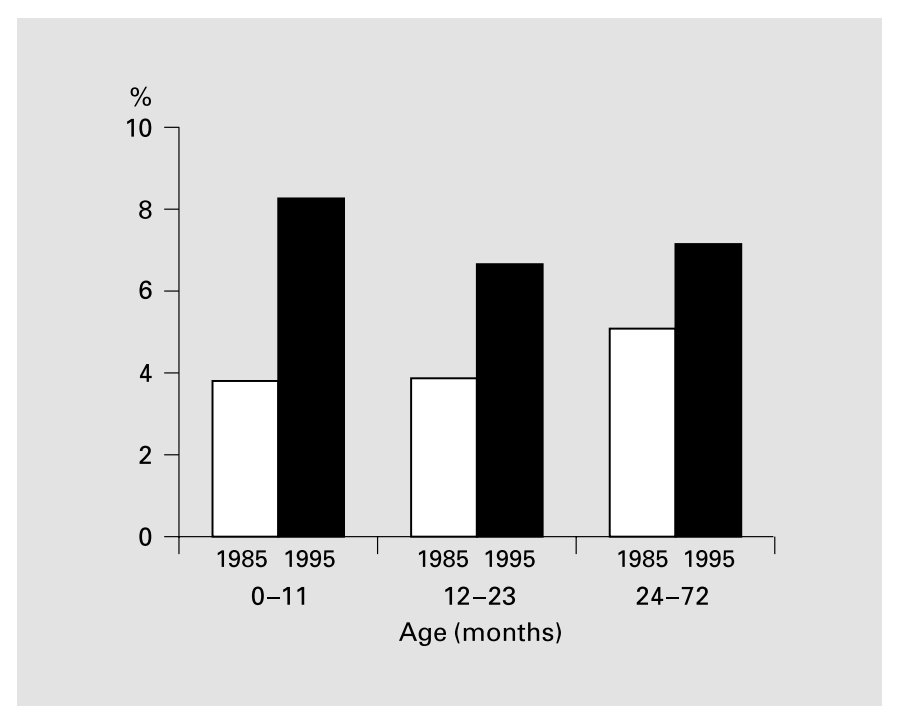

Fig. 1. Trends in childhood obesity in Chile, 1985-1995 [data from C. Albala and F. Vio, 2000].

Table 1. Global prevalence (in millions) of stunting in $<5$-year-old children

\begin{tabular}{lrrr}
\hline & 1980 & 1995 & $\%$ change \\
\hline Sub-Saharan Africa & 26.2 & 42.6 & +62 \\
Northeast-North Africa & 11.3 & 10.9 & -4 \\
South Asia & 88.8 & 89.8 & +1 \\
South-East Asia & 35.5 & 30.2 & -15 \\
Central America-Caribbean & 5.3 & 5.6 & +4 \\
South America & 8.2 & 4.6 & -44 \\
\hline
\end{tabular}

ing) has declined in most areas of the world over the past decade or so. However, marked disparities in child mortality and life expectancy still exist, both between and within countries. As shown in table 1, Sub-Saharan Africa is one of the regions exhibiting an increase in the prevalence of stunting $[2,3]$. Still, nutrition status continues to be the major underlying factor leading to host vulnerability and excess mortality, particularly from measles and diarrheal diseases.

The socio-economic transition that many developing countries are undergoing is also introducing new disease risks that are changing the traditional patterns of nutrition-related diseases in childhood. Urbanization, globalization of food production and marketing, rapid increases in food availability and changing food access are factors favoring the development of diseases traditionally associated with industrialized societies, such as obesity, diabetes, and cardiovascular disease. Although nation-wide longitudinal survey data are still scarce, it seems clear that these conditions are related to the rapid changes in diet and physical activity associated with urbanization. Thus, while some of the changes involved in nutrition transition may be playing a role in alleviating chronic malnutrition, they may be also facilitating the emergence of chronic, non-communicable diseases. Countries in socio-economic transition must face a rapid increase in the prevalence of obesity in children, as is the case of Chile, for example (fig. 1). Because these diseases require long-term medical care and may produce lifetime disability, their impact on the healthcare system and the productivity of developing nations may be considerable.

\section{Nutrition, Disease and Survival}

The health effects of nutritional deficiencies in childhood may be immediate and short term, such as an increased incidence and severity of acute illnesses, particularly diarrheal and respiratory diseases; or may manifest over the longer term, such as impaired rate of growth. The proposed increased risk for chronic, non-communicable diseases in adult life associated with early undernutrition would also fall in this category.

The interaction between nutrition and infection has been the center of attention for half a century $[4,5]$. The evidence of a significant impact of undernutrition on infection is particularly strong for diarrheal and respiratory diseases. In the former, frequency, duration and severity have all been correlated with nutritional status in several prospective studies [6-11]. Undernutrition has also been shown to increase the severity of respiratory infections, particularly in younger children [12].

Vitamin A has earned a prominent role as a child-survival nutrient. From the landmark study of Sommer et al. $[13,14]$ showing that vitamin A supplementation significantly reduced child mortality, a series of clinical trials have confirmed that finding in high-risk populations [1517]. Vitamin A supplementation is an accepted policy to reduce infant mortality in developing countries, as a first step toward food-based strategies to combat vitamin A deficiency.

The role of zinc on child growth and susceptibility to infectious diseases has been known for some time, and recent advances on its role in the cell cycle and immune expression have emphasized its relevance to child health. 
Table 2. Percentage of children who did not achieve the LRNI for micronutrients traditionally added to breakfast cereal and calcium and zinc by breakfast cereal consumption [adapted from 32]

\begin{tabular}{|c|c|c|c|c|c|c|c|c|c|c|c|c|c|c|c|c|}
\hline & \multicolumn{16}{|c|}{ Breakfast cereal consumption, g/day } \\
\hline & \multicolumn{4}{|c|}{$0 \mathrm{~g}$} & \multicolumn{4}{|c|}{$1-20 \mathrm{~g}$} & \multicolumn{4}{|c|}{$21-40 \mathrm{~g}$} & \multicolumn{4}{|c|}{$>41 \mathrm{~g}$} \\
\hline & \multicolumn{2}{|c|}{ boys } & \multicolumn{2}{|c|}{ girls } & \multicolumn{2}{|c|}{ boys } & \multicolumn{2}{|c|}{ girls } & \multicolumn{2}{|c|}{ boys } & \multicolumn{2}{|c|}{ girls } & \multicolumn{2}{|c|}{ boys } & \multicolumn{2}{|c|}{ girls } \\
\hline & 12 & 15 & 12 & 15 & 12 & 15 & 12 & 15 & 12 & 15 & 12 & 15 & 12 & 15 & 12 & 15 \\
\hline Riboflavin & 18 & 15 & 35 & 20 & 0 & 0 & 3 & 6 & 0 & 0 & 0 & 0 & 0 & 0 & 0 & 0 \\
\hline Niacin & 18 & 20 & 13 & 8 & 5 & 0 & 3 & 2 & 0 & 1 & 1 & 0 & 0 & 0 & 3 & 4 \\
\hline Vitamin $B_{12}$ & 0 & 10 & 10 & 8 & 0 & 0 & 0 & 7 & 0 & 1 & 0 & 2 & 0 & 0 & 0 & 0 \\
\hline Folate & 100 & 75 & 94 & 96 & 90 & 86 & 93 & 95 & 89 & 82 & 93 & 80 & 85 & 57 & 76 & 70 \\
\hline Iron & 0 & 0 & 35 & 20 & 0 & 0 & 22 & 17 & 1 & 0 & 13 & 8 & 0 & 0 & 11 & 4 \\
\hline Calcium & 18 & 10 & 32 & 4 & 0 & 0 & 9 & 3 & 0 & 0 & 4 & 0 & 0 & 0 & 3 & 0 \\
\hline Zinc & 0 & 0 & 23 & 2 & 7 & 0 & 7 & 0 & 2 & 0 & 8 & 2 & 0 & 1 & 0 & 0 \\
\hline
\end{tabular}

The early observations of growth faltering in children with low zinc intake [18] have been followed by more recent studies showing modulation of rate of growth by zinc supplementation in otherwise normal infants [19]. Similarly, a number of clinical trials have shown a consistent reduction in the incidence and severity of intestinal and respiratory diseases in children supplemented with zinc [19-21].

In developed countries, the widespread availability of dietary energy is not always matched with proportional availability of micronutrients. This is due to the high proportion of 'empty calories' in the modern urban diet [22]. Thus, during periods of rapid growth and increased micronutrient needs, such as adolescence, marginal micronutrient intakes may become relatively common [23-28]. Some micronutrients such as calcium and iron are particularly sensitive to marginal dietary intake, since their needs increase substantially during the adolescent growth spurt, particularly in women.

Across Europe, iron deficiency is considered to be the main nutrition deficiency disorder [29]. The prevalence of iron depletion or anemia varies considerably both within and between countries. Iron depletion is reported to affect between 2 and $48 \%$ of infants under 2 years of age (2\% Denmark, 25\% Italy, 40\% France, $48 \%$ Spain) and anemia from 2 to $4 \%$ of children aged under 6 years [30]. In the UK alone, $57 \%$ of children under 4 years of age have iron intakes below recommended, resulting in $20 \%$ of pre-school children having low iron stores and $8 \%$ with iron deficiency anemia [31]. During adolescence, onefifth of teenage girls are reported to be iron-deficient across Europe ( $43 \%$ of Irish girls aged $14-15$ years; $28 \%$ of
12- to 13 -year-old British girls; $15 \%$ of Swedish girls aged $14-17$ years; $15 \%$ of 12 - to 13 -year-old Danish girls; $15 \%$ of French 14- to 18 -year-old girls and $11 \%$ of Italian girls aged 11-15 years) [30]. Nutritional changes to prevent and correct this widespread nutritional deficiency are vital, as even marginal deficiencies have been shown to adversely affect growth, development and learning.

Along with healthier eating practices, fortification of selected food items with micronutrients can play a role in reducing risk of deficiencies in these at-risk populations.

The efficacy of single food fortification has been demonstrated by McNulty et al. [32] in their examination of the micronutrient intakes of adolescents in relation to intake of breakfast cereal - a food that is commonly fortified with vitamins and minerals within Europe. Overall, mean intakes of micronutrients by over 1,000 boys and girls aged 12-15 years appeared to be adequate, with the exception of folate (boys and girls) and iron (girls only). However, appreciable numbers had daily intakes below the Lower Reference Nutrient Intake (LRNI), the incidence of which increased significantly among those children who were not consuming fortified breakfast cereals daily (table 2). The LRNI of any nutrient is the amount estimated to meet the needs of the bottom $3 \%$ of the population. If individuals habitually eat less than this amount they will almost certainly be deficient [33]. These results demonstrate the potential of food fortification in contributing to the micronutrient intakes of schoolchildren, and particularly where diet quality is low or marginal. 


\section{Early Nutrition and Adult Disease}

Until recently, the long-term effects of early malnutrition were understood only in terms of its irreversible effects on growth and development. More recently, the hypothesis that early nutritional deficiencies, even when transient, may affect long-term disease risk, possibly by modifying cellular differentiation and/or function at critical stages of development, has been put forward, primarily based on descriptive epidemiological data. The finding of an inverse correlation between birth weight and prevalence of type II diabetes by Barker et al. [34, 35] has prompted much interest in this area. Other studies have also found a relationship between childhood stunting and adult central adiposity, which is a known risk factor for insulin resistance and type 2 diabetes [36]. The suggestion that early nutritional deficiencies cause an irreversible 'metabolic imprinting' is also supported by the finding of impaired fat oxidation in children who were previously malnourished [37]. Although the implications of these findings for developing countries with high rates of childhood malnutrition remain unclear, they form an important aspect of the potential adverse effects of early nutritional deficiencies on human health.

\section{Conclusions}

While the progress in reducing global infant mortality and the success of child survival programs must be recognized, the new, emerging challenges on child health are no less evident. Single or multiple micronutrient deficiencies are still widespread, and some of these, for example iron deficiency, also affect important segments of the population in developed countries. Thus, strategies to enhance micronutrient intake during infancy and childhood throughout the world must continue to be a priority for government, health policy-makers, school services, caregivers and parents. Food fortification, supplementation programs, and marketing strategies are all options currently available.

Another challenge is the emergence of non-communicable diseases in the developing world. The notion that fetal and early postnatal malnutrition can significantly increase the risk for chronic diseases in adulthood underscores the public health relevance of continued efforts to insure adequate nutrition and growth in childhood.

\section{References}

1 Prevention and Control of Iron Deficiency in Women and Children: Report of the UNICEF/ WHO Regional Consultation. United Nations Children's Fund, 1999.

2 Administrative Committee on Coordination Sub-Committee on Nutrition: Third Report on the World Nutrition Situation, Geneva 1997.

3 West KP, Caballero B, Black RE: Nutrition; in Merson M, Black RE, Mills AJ (eds): International Public Health. Gaithersburg, Aspen Publishers, 2000, pp 207-291.

4 Scrimshaw NS, Taylor CE, Gordon JE: Interactions of Nutrition and Infection. Geneva, WHO, 1968.

5 Tomkins AM: Protein energy malnutrition and risk of infection. Proc Nutr Soc 1986;45:289304.

6 Yoon PW, Black RE, Moulton LH, Becker S: The effect of malnutrition on the risk of diarrheal and respiratory mortality in children $<2$ years of age in Cebu, Philippines. Am J Clin Nutr 1997;65:1070-1077.

7 Black RE, Brown KH, Becker S: Malnutrition is a determining factor in diarrheal duration, but not incidence, among young children in a longitudinal study in rural Bangladesh. Am J Clin Nutr 1984;37:87-94.
8 James JW: Longitudinal study of the morbidity of diarrheal and respiratory infections in malnourished children. Am J Clin Nutr 1972;25: 690-694.

9 Palmer DI, Koster FT, Alam AKMJ, Islam MR: Nutritional status: A determinant of severity of diarrhea in patients with cholera. $\mathrm{J}$ Infect Dis 1976;134:8-14.

10 Tomkins AM: Nutritional status and severity of diarrhea among preschool children in rural Nigeria. Lancet 1981;i:860-862.

11 Victoria CG, Barros FC, Kirkwood BR, Vaughan JP: Pneumonia, diarrhea, and growth in the first 4 years of life: A longitudinal study of 5,914 urban Brazilian children. Am J Clin Nutr 1990;52:391-396.

12 Johnson WB, Aderele WI, Gbadero DA: Host factors and acute lower respiratory infections in pre-school children. J Trop Pediatr 1992;38: 132-136.

13 Sommer A, Tarwotjo I, Hussaini G, Susanto D: Increased mortality in children with mild vitamin A deficiency. Lancet 1983;ii:585-588.

14 Sommer A: Vitamin A status, resistance to infection, and childhood mortality. Ann NY Acad Sci 1990;587:17-23.
15 Coutsoudis A, Broughton M, Coovadia HM: Vitamin A supplementation reduces measles morbidity in young African children: A randomized, placebo-controlled, double-blind trial. Am J Clin Nutr 1991;54:890-895.

16 Frieden TR, Sowell AR, Henning KJ: Vitamin A levels and severity of measles. Am J Dis Child 1992;146:182-186.

17 Hussey GD, Klein MA: A randomized, controlled trial of vitamin A in children with severe measles. N Engl J Med 1990;323:160_ 164.

18 Prasad AS, Halsted JA, Nadhimi M: Syndrome of iron deficiency anemia, hepatosplenomegaly, dwarfism, hypogonadism and geophagia. Am J Med 1961;31:532-546.

19 Walravens PA, Hambidge KM, Koepfer DM: Zinc supplementation in infants with a nutritional pattern of failure to thrive: A doubleblind, controlled study. Pediatrics 1989;83: 532-538.

20 Bhutta ZA, Black RE, Brown KH, et al: Prevention of diarrhea and pneumonia by zinc supplementation in children in developing countries: Pooled analysis of randomized controlled trials. Zinc Investigators' Collaborative Group. J Pediatr 1999;135:689-697. 
21 Golden M, Golden B: Effect of zinc supplementation on the dietary intake, rate of weight gain, and energy cost of tissue deposition in children recovering from severe malnutrition. Am J Clin Nutr 1981;34:900-908.

22 Frazao E: America's Eating Habits. Changes and Consequences. Washington, USDA, 1999.

23 Potier de Courcy G, Maffre J, et le membres du Groups Travail de la CEDAP: Estimation du statut en vitamines et minéraux de la population Française, d'après des enquêtes récentes. Cah Nutr Diet 1999;34:77-87.

24 Hercberg S, et al: Apports nutritionnels d'un échantillon réprésentatif de la population du Val-de-Marne. III. Les apports en minéraux et vitamines. Rev Epidémiol 1991;39:245-261.

25 Frank G, et al: Die Nationale Verzehrsstudie Projektträger Forschung im Dienste der Gesundheit, 1991.
26 Zo eet Nederland: Resultaten ven de voedsel consumtiepeiling 1997-1998.

27 Becker w Belfolkningens kostvanor och naringsintag: Food habits and nutrient intake in Sweden 1989. Var Foda 1992;44:349-362.

28 Gregory J, Lowe S: National Diet and Nutrition Survey: Young people aged 4-18 years. London, The Stationery Office, 2000.

29 Hallberg L: Results of surveys to assess iron status in Europe. Nutr Rev 1995;11:314-322.

30 Hercberg S, Preziosi P, Galan P: Iron deficiency in Europe. Public Health Nutr 2001;4:537545.

31 Gregory J, Lowe S: National Diet and Nutrition Survey: Children aged 1.5-4.5 years. London, The Stationery Office, 1995.

32 McNulty H, Eaton-Evans J, Cran G, Woulahan G, Boreham C, Savage MJ, Fletcher R, Strain $\mathrm{J}$ : Nutrient intakes and impact of fortified breakfast cereals in schoolchildren. Arch Dis Child 1996;75:474-481.
33 Department of Health: Dietary reference values for food energy and nutrients for the United Kingdom. London, The Stationery Office, 1991.

34 Barker DJP: The effects of nutrition of the fetus and neonate on cardiovascular disease in later life. Proc Nutr Soc 1992;51:135-144.

35 Phillips DIW, Barker DJP, Hales CN, Hirst S, Osmond C: Thinness at birth and insulin resistance in adult life. Diabetologia 1994;37:150 154.

36 Schroeder DG, Martorell R, Flores R: Infant and child growth and fatness and fat distribution in Guatemalan adults. Am J Epidemiol 1999; 149:177-185.

37 Hoffman DJ, Sawaya AL, Verreschi I, Tucker KL, Roberts SB: Why are nutritionally stunted children at increased risk of obesity? Studies of metabolic rate and fat oxidation in shantytown children from Sao Paulo, Brazil. Am J Clin Nutr 2000;72:702-707. 